\title{
MICRO E PEQUENAS EMPRESAS: RELEVÂNCIA ECONÔMICA E SUAS PRINCIPAIS CAUSAS DE MORTALIDADE NO ESTADO DE SÃO PAULO
}

Luana Santos Mateo, Wilson de Luces Fortes Machado.

Centro Universitário Antônio Eufrásio de Toledo de Presidente Prudente, Curso de Ciências Contábeis, Presidente Prudente, SP. E-mail: luanasantosmateo@hotmail.com

\section{RESUMO}

Este artigo analisa e une informações a respeito da relevância econômica dessas Micro e Pequenas Empresas situadas no Estado de São Paulo, bem como as causas da mortalidade precoce desses Pequenos Negócios. A metodologia foi baseada em pesquisa bibliográfica. Os resultados encontrados foram o altíssimo grau de importância que essas Empresas concebem a economia brasileira. Concluímos que é necessária a adoção de medidas que colaborem com esse tipo de Negócio, como consultorias, potencializando sua permanência no mercado, dado a alto grau de mortalidade destas empresas.

Palavras-chave: Impactos, Empresas, SEBRAE, Taxa de Sobrevivência, Economia.

\section{MICRO AND SMALL ENTERPRISES: ECONOMIC RELEVANCE AND ITS MAIN CAUSES OF MORTALITY IN SÃO PAULO STATE}

\begin{abstract}
This article analyzes and combines information on the economic relevance of Micro and Small Enterprises located in the State of São Paulo, as well as the causes of premature mortality of Small Business. The methodology was based on literature. The results were the high degree of importance that these companies conceive the Brazilian economy. We conclude that the adoption of measures that contribute to this type of business is needed, such as consulting, enhancing their stay in the market, given the high level of mortality of these companies.
\end{abstract}

Keywords: Impacts, Companies, SEBRAE, Survival Rate, Economy. 


\section{INTRODUÇÃO}

Nos últimos anos, o número de abertura de empresas Micro e Pequenas Empresas (MPEs) crescemam em larga escala. Agências de assessoria que analisam e controlam estatisticamente estes dados (abertura de empresas), trabalham ativamente para demonstrar a sociedade e demais interessados o desenvolvimento e dificuldades encontradas por essas novas empresas.

Pelos resultados de pesquisas, vê-se o grau de importância que esses tipos de negócios trazem para o desenvolvimento de todo o país. Entretanto as vidas úteis destas empresas causam preocupação. As principais causas de mortalidade são falhas gerenciais, como, falta de planejamento financeiro/tributário, má gestão e desconhecimento do próprio negócio. O Jornal do Commercio mostra as 7 (sete) pecados que as empresas:

Cálculo inadequado de capital de giro e de estoque, falhas no planejamento orçamentário, inexperiência no ramo escolhido, problemas no contrato de locação, incompatibilidade entre sócios, fatos macroeconômicos e escolha e ponto errado. Podem até ser primarias, mas essas falhas foram os principais pecados cometidos em negócios que acabaram fracassando. (Os 7 pecados das pequenas empresas. Jornal do Commercio, 12 jul. 2000, p B-20).

É fundamental que os empresários busquem orientações em agências que prestam serviços de consultoria, e também dos profissionais de Contabilidade, para que consigam atuar no mercado de maneira eficiente, obtendo, consequentemente, o sucesso almejado.

O objetivo deste estudo foi agrupar as informações, mencionando o quanto são importantes, suas contribuições e causas de mortalidade, devido às consequências que são tratadas no decorrer deste artigo.

\section{METODOLOGIA}

A metodologia utilizada para a pesquisa concentrara-se em pesquisa bibliográfica, extraídas de sites de empresas que prestam Consultoria e acompanham todo o andamento das Micro e Pequenas Empresas, localizadas no Estado de São Paulo, com embasamento qualitativo e quantitativo sobre a criação, impactos e principais Causas de Mortalidade.

\section{RESULTADOS}

Os resultados encontrados demostram o alto nível de necessidade de contar com MPEs dentro do mercado brasileiro, visto que, são estas que fomentam e aquecem indicadores, como o PIB (Produto Interno Bruto), e setores que geram massa de salário à toda sociedade.

Gráfico 01. Participação das MPEs na economia Estado de São Paulo -2014

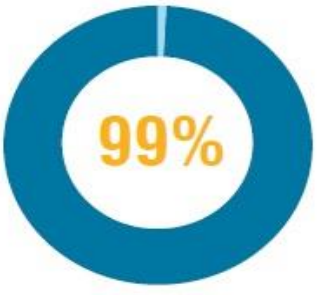

Estabelecimentos

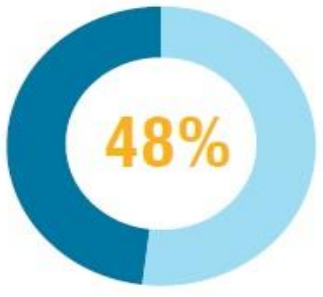

Empregos

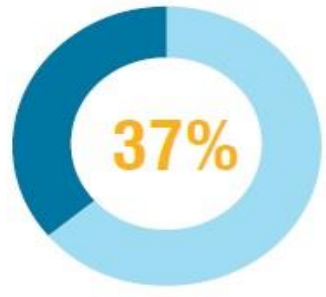

Folha de salários
Micro e pequenas empresas

Médias e grandes empresas

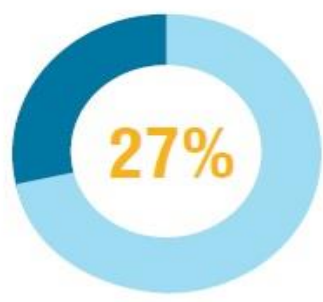

Produto Interno Bruto

Fonte: Elaborado pelo Sebrae-SP/ Gestão Estratégica, a partir da RAIS/ MTE (2014) e Sebrae-NA/ FGV (2015). 
Destaca-se no gráfico acima: de todos os estabelecimentos presentes no Estado de São Paulo, 99\% são constituídas de Micro e Pequenas Empresas, ou seja, o percentual de Médias e Grandes Empresas é representado por apenas $1 \%$ da totalidade.

Indicadores, como o PIB (Produto Interno Bruto), também contribui com o enriquecimento vindo das Micro e Pequenas Empresa, cerca de 27\%. Da mesma forma, estes estabelecimentos cooperam para a geração de renda e empregabilidade da população.

LONGENECKER, Moore e Petty (1997), apontam algumas contribuições que as MPEs trazem para o meio em que estão inseridas, tais como, geração de novos empregos, fonte de inovação, estimula competição econômica, auxilia as grandes empresas e possuem produção eficiente de bens e serviços.

Mesmo com alto grau de importância que as pequenas empresas possuem, políticas macroeconômicas são dirigidas para grandes empresas e exigências do mercado financeiro que, em grande parte, contribuem para o enfraquecimento das MPEs.

O foco das medidas esta sobre crescimento econômico, controle da inflação, ajuste das contas publicas, que se alteram no médio e até curto prazo, contribuindo para as dificuldades do planejamento empresarial das empresas que são o objeto estudo.

\section{DISCUSSÃO}

Como já citado acima, a economia brasileira é aquecida, não somente por empresas de grande porte, mas também, constituída de pequenos negócios que fomentam o desenvolvimento do país, e geram impactos expressivos e positivos em todo território nacional.

O número de estabelecimentos optantes pelo Simples Nacional ${ }^{1}$ aumenta a cada ano, como é apresentado nas pesquisas realizadas pelo SEBRAE (Serviço Brasileiro de Apoio às Micro e Pequenas Empresas). Segundo a Cartilha Sobrevivência das Empresas no Brasil, do SEBRAE, publicado no ano de 2013, em dezembro de 2012, constatou-se que em cerca de 7,1 milhões de empresas eram registradas nesse regime.

O SEBRAE revela a importância e benefícios trazidos com a constituição desse tipo de Negócio:

O crescimento do número de novas empresas, se associa à melhoria na competitividade, tende a gerar impactos expressivos na economia brasileira, seja em termos de maior oferta de empregos, melhores salários, ampliação da massa salarial e da arrecadação de impostos, a melhor distribuição de renda e o aumento de bem-estar social. (Cartilha Sobrevivência das Empresas no Brasil, 2013, p.7).

É de extrema necessidade contar com essas empresas, pois trazem inúmeros benefícios, não só para a economia, mas também para a sociedade em geral, visto quem estas geram empregabilidade, contribuem para indicadores econômicos, como o PIB e, consequentemente, alavanca a competição econômica brasileira.

\section{SETORES DAS MPES NA ECONOMIA PAULISTA}

As Micro e Pequenas Empresas são distribuídas em setores de atividades, são eles: Setor de Serviços, Comércio, Agropecuária, Indústria e Construção ${ }^{2}$. Porém, o ramo de atividade que se destaca é de Serviços, com 914.093 mil MPEs, distribuídas em todo Estado paulista. Logo em seguida, segue o Setor de Comercio, com 855.876 mil, perdendo apenas $2 \%$ de diferença entre o

\footnotetext{
${ }^{1}$ A Receita Federal traz que o Simples Nacional nada mais é que um regime de arrecadação, cobrança e fiscalização de tributos aplicável às Microempresas e Empresas de Pequeno Porte, previsto na Lei Complementar $n^{\circ} 123$, de 14 de dezembro de 2006.

${ }^{2}$ Dado Elaborado pelo SEBRAE-SP/ Gestão Estratégica, a partir da RAIS/ TEM (2014) e Censo Agropecuário/ IBGE (2006). 
maior Setor (Serviços). Já empresas nos Setores Agropecuários, Indústria e Construção, somam $22 \%$ da totalidade.

\section{MORTALIDADE DAS EMPRESAS}

No Estado de São Paulo, cerca de 150 mil empresas são registradas anualmente no $\mathrm{CNPJ}^{3}$ (Cadastro Nacional da Pessoa Jurídica). Em contrapartida, segundo dados do SEBRAE em pesquisa sobre MPEs paulistas, 2 em cada 10 empresas registradas no CNPJ acabam fechando antes de completarem os dois primeiros anos de vida, apontando que apenas $78,1 \%$ das MPEs sobrevivem a eles.

\section{PRINCIPAIS FATORES RESPONSÁVEIS}

Inúmeras dificuldades são encontradas pelas MPEs nos primeiros anos de vida e na opinião de alguns empresários a falta de clientela, falta de capital, concorrência, burocracia, altos impostos, são as principais dificuldades vividas por essas empresas. Segundo CHIAVENATO, Idalberto (2005), vários cuidados devem ser observados no momento da abertura do novo negócio, tais como, identificar adequadamente seu tipo de negócio, saber administrar o andamento das operações, conhecer mercado, dentre outras informações essenciais.

Segundo uma pesquisa desenvolvida pelo SEBRAE, Causa Mortis: o sucesso e o fracasso das empresas nos primeiros cinco anos de vida, os três principais fatores responsáveis pela mortalidade das empresas não estão relacionados ao ambiente onde a empresa atua, são fatores ligados à ação do empreendedor.

\section{PLANEJAMENTO PRÉVIO}

Segundo a pesquisa citada acima, parte dos empreendedores não levantaram informações importantes sobre o mercado, não realizaram planejamento de itens básicos antes do início das atividades da empresa e não se preocuparam em fazer um planejamento de maior tempo para aumentarem suas chances de sucesso. Cerca de $39 \%$ não tinham o capital de giro necessário para abrir o negócio, 38\% não sabiam o número de concorrentes que teriam, 33\% não tinha informações sobre fornecedores e 32\% não conhecia os aspectos legais do negócio.

\section{GESTÃO EMPRESARIAL}

No aspecto de gestão dessas empresas, falta aos empreendedores o hábito de aperfeiçoar produtos e serviços, investir em capacitação, estar atualizado com respeito às novas tecnologias, adquirir conhecimento sobre segmento que atua e estratégia de diferenciação que aumenta muito as chances de se manterem no mercado e crescer.

\section{COMPORTAMENTO EMPREENDEDOR}

Outro motivo para as MPEs não durarem é os empreendedores não se comportarem como tais. Segundo o SEBRAE, é importante que o empreendedor na sua busca pela permanência e sucesso se antecipe aos fatos, sempre busque informações, persista nos objetivos, desenvolva plano de ações para alcançar seus objetivos e intensifique contato com outras empresas, bancos e o governo. Além disso cabe ao empreendedor desenvolver o relacionamento interpessoal, pois $9 \%$ dos que fecharam alegaram problemas particulares e $7 \%$ alegaram que a causa do fechamento foi problemas com sócios.

\section{CONCLUSÃO}

\footnotetext{
${ }^{3}$ Dado Elaborado pelo SEBRAE-SP/ Gestão Estratégica, a partir da RAIS/ TEM (2014) e Censo Agropecuário/ IBGE (2006). 
Vemos que as MPEs exercem um papel econômico de alta relevância em todo o país, alavancando e gerando empregabilidade, renda e nutrindo positivamente com indicadores econômicos, que fortalecem o Brasil.

Em comparação com as Médias e Grandes Empresas situadas no estado de São Paulo, os Pequenos Negócios representam 99\% da totalidade. Porém esta outra parcela de minoria (grandes empresas), são as que influenciam nos programas de políticas macroeconômicas do Brasil, desvitalizando o poder que as MPEs podem exercer.

Visto o grau de importância das Micro e Pequenas Empresas no Estado de São Paulo, é necessário que as politicas econômicas do governo somem forças em conjunto com esses empreendedores para promover maior incentivo à criação e permanência dessas empresas no mercado, além disso, é significativo que os empresários busquem capacitação, informação, orientação e dicas para garantir a longevidade nos negócios. Uma boa gestão e um serviço de contabilidade qualificado é um dos pilares fundamentais para prosperidade e sobrevivência das empresas.

\section{REFERÊNCIAS}

ABRA SEU NEGÓCIO. Mortalidade de Micro e Pequenas Empresas: Fatores que levam a falência precoce. 2016. Disponível em: <http://www.abraseunegocio.com.br/2016/02/mortalidade-demicro-e-pequenas-empresas-fatores-que-levam-a-falencia-precoce/> Acesso em: 06 ago. 2016.

CHIAVENATO, Idalberto. Gerenciando com as pessoas. 5. ed. São Paulo: Saraiva, 2014.

CHIAVENATO, Idalberto. Empreendedorismo: Dando asas ao espírito empreendedor. 2. ed. São Paulo: Saraiva, 2008.

EXAME. Porque as empresas fecham? Disponível em: <http://exame.abril.com.br/pme/noticias/por-que-as-empresas-fecham> Acesso em: 06 ago. 2016.

LONGENECKER, Moore Petty. Administração de pequenas empresas. 13. ed. Makron Books, 1997.

MARION, José Carlos. Análise das demonstrações contábeis. 7. ed. São Paulo. Editora Atlas, 2012.

SEBRAE. Causa mortis: Sucesso e o fracasso das empresas nos primeiros 5 anos de vida. 2014. Disponível

em: <http://www.sebraesp.com.br/arquivos_site/biblioteca/EstudosPesquisas/mortalidade/causa_mo rtis_2014.pdf> Acesso em: 22 jul. 2016.

SEBRAE. Panorama das MPEs paulistas 2016. Disponível em: <http://www.sebraesp.com.br/arquivos_site/biblioteca/EstudosPesquisas/mpes_numeros/book_ pesquisa_sobre_mpes_paulistas_fe_2016.pdf> Acesso: em 15 jul. 2016.

SEBRAE. SEBRAE nas cidades. Disponível em: <http://www.sebrae.com.br> Acesso em: 22 jul. 2016.

SEBRAE. Sobrevivência das empresas no Brasil. 2013. Disponível em: <http://www.sebrae.com.br/Sebrae/Portal\%20Sebrae/Anexos/Sobrevivencia_das_empresas_no_ Brasil=2013.pdf> Acesso: em 15 jul. 2016. 